\title{
EL AMBIENTALISMO Y LA LUCHA CONTRA EL COMBO DEL SECTOR ELÉCTRICO $(1998-2001)^{1}$
}

\section{ENVIRONMENTALISM AND ELECTRICITY SECTOR REFORM IN COSTA RICA (1998-2001)}

\author{
Rafael E. Cartagena*
}

RESUMEN

En el año 2000, una parte del ambientalismo se sumó al movimiento de rechazo a la ley de privatización del Instituto Costarricense de Electricidad (ICE) llamada popularmente el Combo sobre el sector eléctrico costarricense. Su aporte no se puede medir en la cantidad de afiliados o activistas que movilizó, si no por haber formulado una crítica ecológica y una crítica distributiva de los cambios en el sector eléctrico. El caso también ilustra los alcances y límites de las coincidencias entre el ambientalismo y demás movimientos sociales en Costa Rica.

PALABRAS CLAVE: COSTA RICA * MOVIMIENTOS SOCIALES * MEDIO AMBIENTE * ENERGÍA ELÉCTRICA * POLÍTICA ENERGÉTICA * PRIVATIZACION

\section{ABSTRACT}

In the year 2000, one part of the environmental movement of Costa Rica joined forces with labor unions, community groups and other social sectors in a national struggle against el Combo, a proposal of reform affecting the public electric sector. The environmentalist's contribution to this movement can be understood as double critique of the intended reform: an ecological critique and a distributive critique. The struggle against el Combo also illustrates the scope and limits of such socialenvironmental alliances.

KEY WORDS: COSTA RICA * SOCIAL MOVEMENTS * ENVIRONMENT * ELECTRIC POWER * ENERGY POLICY * PRIVATIZATION

Este artículo se basa en una parte de la tesis de Doctorado del autor, titulada Metabolismo socio-natural y conflictos ambientales en Costa Rica y El Salvador, 1992-2007 (FLACSO, Posgrado Centroamericano en Ciencias Sociales, 2009).
Área de investigación de la Fundación PRISMA (El Salvador). rafa.semueve@gmail.com 


\section{INTRODUCCIÓN}

En el año 2010 se cumple una década de la lucha contra el Combo, la masiva movilización popular que en su momento detuvo la privatización del mercado de las telecomunicaciones y electricidad en Costa Rica. Este artículo se ocupa de la participación del sector ambientalista en dos etapas de esa lucha: en las acciones de cabildeo y movilización, hasta abril del 2000, y en el proceso posterior de elaboración de una propuesta de Ley de Fortalecimiento del Instituto Costarricense de Electricidad (ICE), concertada por distintos sectores del movimiento social ${ }^{2}$.

En la primera parte del artículo se ofrece un relato acerca de las acciones emprendidas por el sector ambientalista. Luego se analizan el contenido de la crítica ambientalista frente al Combo y las posturas defendidas durante la elaboración de la propuesta de la Ley de Fortalecimiento del ICE. En la parte final se analizan los alcances y límites de las coincidencias que favorecieron la colaboración entre ambientalistas $y$ otros sectores sociales en dicho proceso.

Las fuentes consultadas fueron principalmente de tipo personal: una decena de entrevistas con luchadores y luchadoras sociales que tomaron parte en el movimiento contra el Combo. Ello se complementó con algunos documentos elaborados por el movimiento, tales como correspondencia, informes internos y documentos públicos. Adicionalmente, también se consultaron medios de prensa de la época.

\section{PARTICIPACIÓN DEL SECTOR AMBIENTALISTA EN EL CONFLICTO}

Combo fue el nombre con el que se conoció el proyecto de ley "Mejoramiento de los Servicios Públicos de Electricidad y Telecomunicaciones y de la participación del

$2 \quad$ Se trata de la propuesta de Ley de Fortalecimiento del ICE, elaborada por la Representación Social ante la Comisión Mixta de la Asamblea Legislativa, entre abril y octubre del 2000.
Estado" (Asamblea Legislativa, 2000). Combo porque reunió en un sólo texto varias propuestas de ley que modificaban la estructura $y$ potestades del Instituto Costarricense de Electricidad (ICE).

Dichas leyes comenzaron a elaborarse en $1996^{3}$. Los sectores preocupados por la apertura $y$ desregulación utilizaron distintos mecanismos del proceso legislativo para modificar estos proyectos. La Asociación Conservacionista Yiski fue la primera agrupación que aprovechó ese recurso. Yiski es una pequeña organización de voluntarios, profesionales en su mayoría, orientada a la denuncia y capacitación ambiental (Fournier, 2007: entrevista). En aquel momento formaba parte de una alianza que se llamó Frente Nacional por los Bosques (FNB), donde también sobresalía APREFLOFAS ${ }^{4}$, una Organización No Gubernamental (ONG) ambientalista de tamaño mediano en el contexto costarricense. Fueron un asociado de APREFlofas y Yiski, junto a la Presidenta de esta Asociación, quienes comenzaron a visitar y enviar notas a diputados/as de la Asamblea Legislativa, a mediados de $1998^{5}$. Las primeras gestiones se hicieron a nombre de Yiski, después a nombre del FNB (Portilla, s.f.; $y$ entrevistas: Portilla, 2007; Fournier, 2007).

Yiski, APREFLOFAS y otras agrupaciones del Frente por los Bosques pertenecían a $\mathrm{FECON}^{6}$, que en aquel entonces reunía a 25 agrupaciones. También estaba afiliada a FECON la Red Costarricense de Reservas Naturales (RCRN), que asociaba a 84 reservas privadas dedicadas a la conservación, ecoturismo y acti-

3 Comprendía en sus orígenes tres proyectos (Ley General de Electricidad, Ley de Telecomunicaciones y Ley de Modernización del ICE), presentados en agosto de 1996 por el gobierno de Figueres Olsen (1994-1998, Partido Liberación Nacional) y retomados por el Presidente Rodríguez (1998-2002, Partido Unidad Social Cristiana).

4 Asociación Preservacionista de Flora y Fauna Silvestre.

5 Se trataba de Rolando Portilla y de María Elena Fournier, conocidos ambientalistas.

$6 \quad$ Federación Costarricense para la Conservación del Ambiente. 
vidades científicas (FECON y RCRN, 1999). En noviembre de 1998, estas organizaciones fueron recibidas por la Comisión de Gobierno y de Administración de la Asamblea Legislativa (Portilla, 2007: entrevista; Portilla, s.f.).

Los señalamientos se dirigían a uno de los componentes del Combo, la propuesta de Ley General de Electricidad. Esta recibió un dictamen favorable por parte de los diputados el día 18 de noviembre de 1998 (Portilla, s.f.; Méndez, 1998). Al año siguiente, continúa Portilla (s.f.), "seguimos la lucha, y continuamos enviando notas a diputados, así como a otros sectores". También FECON y la Red de Reservas continuaron remitiendo notas con mociones de reforma (FECON y RCRN, 1999). Por otra parte, en el año 1999 se sumó a estos esfuerzos el Comité de Defensa de los Ríos de Pérez Zeledón, grupo que tiene su origen en la lucha varias familias amenazadas con la expropiación de sus tierras para abrir paso a un proyecto hidroeléctrico privado en aquella zona del país (Ureña, 2007: entrevista).

A finales de 1999 ninguno de los proyectos estaba listo para su debate en el plenario del Congreso. Para acelerar su aprobación fueron fusionados bajo una sola propuesta. El 20 de diciembre de 1999, los diputados de los partidos PUSC y PLN terminaron de elaborar un texto de común acuerdo y lo aprobaron en Comisión. Así se allanaba el camino para su debate en el plenario del Congreso.

Al día siguiente de ello, varios sectores se presentaron a una reunión promovida por el diputado José Merino: hasta ese momento los distintos grupos habían "trabajado en forma separada" (Fournier, 2007: entrevista), de modo que "allí comenzamos a conocernos. Allí comenzó la primera organización" (Portilla, 2007: entrevista). El comunicado elaborado recoge varias críticas al Combo, incluyendo la cuestión ambiental:

Esto implica el principio del desmantelamiento del ICE, la entrega de los negocios de energía y telecomunicaciones a manos de las transnacionales, la entrega de nuestras riquezas naturales y el deterioro del medio ambiente, $y$ fundamentalmen- te aumentos de las tarifas eléctricas y de telecomunicaciones para todos los costarricenses ${ }^{7}$.

Las discusiones en el plenario legislativo reiniciaron el lunes 24 de enero (Venegas, 2000). Ese día FECON publicó sus objeciones al Combo en un campo pagado en La Nación (FECON, 2000b; Herrera y Vargas, 2000). Además de las 25 organizaciones de la Federación, suscribieron ese manifiesto el Frente Nacional por los Bosques, la Coordinadora de Comunidades y Organizaciones No Gubernamentales para la Defensa de las Cuencas Hidrográficas y la Red Costarricense de Reservas Naturales. El resto de la semana fue de cabildeo intenso, procurando que el Congreso acogiera un conjunto de mociones presentadas por el sector ambientalista ${ }^{8}$. Estos fueron los últimos esfuerzos en la Asamblea Legislativa, pues a partir de allí sólo quedaba esperar por la suerte de las enmiendas, acogidas por algunos diputados (Macdonald, 2007: entrevista).

El país estaba entrando en un clima de "efervescencia". A mediados de marzo se presentaron movilizaciones campesinas en demandas propias del sector. Estas acciones cesaron por la intervención policial, pero se acrecentaron las marchas por la inminente aprobación del Combo en el plenario legislativo, lo que

$7 \quad$ El documento fue firmado por Albino Vargas (ANEP) y Rafael Mora (UPINS), a nombre del Comité Sindical Nacional. Alonso Araya, por el Frente Interno de Trabajadores del ICE. Ma. E. Fournier, por el Frente Nacional por los Bosques. Pilar Ureña, por la Coordinadora de Comunidades y ONG por la Defensa de las Cuencas Hidrográficas. Eva Carazo, por la Federación de Estudiantes Universitarios de la UCR. Y el diputado José Manuel Núñez, por el Partido Fuerza Democrática.

8 A lo interno de FECON varias personas habían organizado un equipo de trabajo para analizar el proyecto y proponer enmiendas. La Directora Ejecutiva de aquel entonces recuerda que participaron en ese equipo Johny Rosales de la Asociación Conservacionista Monteverde, Amos Bien y Martha Marín de la Red de Reservas Privadas, Rocío López por ABAS, Ma. Elena Fournier por Yiski, Franklin Paniagua por CEDARENA, Isaac Rojas de COECO-Ceiba, Émile Rojas, Presidente de FECON (Macdonald, 2007: entrevista; FECON, 2000). 
ocurrió la noche del 20 de marzo. A partir del día siguiente se sucedieron 14 días de movilizaciones populares en todo el país. La principal forma de protesta fueron los bloqueos de calle. Pero también se dieron paros de labores que afectaron las universidades estatales, puertos e instituciones públicas. En la entrada del edificio principal del ICE, cuatro estudiantes universitarios se mantuvieron en huelga de hambre por más de ocho días (Fuentes, 2001).

Al llegar a su segunda semana, el movimiento se mostraba más diverso y fortalecido. Así, el 31 de marzo se realizó un encuentro de agrupaciones comunales y políticas bautizado Foro Nacional "Jesús Martínez"9. Allí estuvieron, entre otros, el Frente de Oposición a la Minería de Oro a Cielo Abierto de la Zona Norte, y la Unión de Amigos para la Protección del Ambiente, de Pérez Zeledón. También la Asociación Ecologista de Cogestión Comunitaria, una de las escisiones de la antigua $\mathrm{AECO}^{10}$. Luego, el 3 de abril inició una Huelga Nacional, que paralizó el puerto de Limón. Ese día se reportaron unos 30 bloqueos fuera del Valle Central (Se Mueve, 2000a; 2000b).

Las movilizaciones cesaron el 4 de abril, día en que se realizó el llamado Diálogo Nacional, entre los sectores adversos al proyecto, diputados y ministros de Gobierno. Allí se acordó suspender el proceso de aprobación de la ley y conformar una Comisión Especial Mixta en la Asamblea Legislativa, —con participación de diputados $y$ representantes sociales cuyo mandato era modificar o elaborar algún tipo de alternativa para "mejorar" o "modernizar" el ICE (Acuerdo del Diálogo Nacional, 2000¹).

$9 \quad$ Jesús Martínez fue el agricultor que murió el día 16 de marzo, atropellado por un conductor durante un bloqueo de carreteras.

10 Asociación Ecologista Costarricense. Fue la organización ambientalista más beligerante en la primera parte de la década de 1990. Se disolvió en el año 1999.

11 La "Comisión Mixta" — como se le llamó- terminó sus funciones en noviembre de 2001. Se organizó una segunda Comisión Mixta en el año 2004, no contemplada en esta investigación.
El Acuerdo fue firmado por representantes de distintos sectores, entre ellos el Presidente de FECON, en representación del sector ambientalista. Ello no deja de ser contradictorio pues con excepción de algunas de sus organizaciones y funcionarios a título individual, la Federación como entidad se abstuvo de participar en las movilizaciones de calle (entrevistas: Macdonald, 2007; Cárdenas, 2007). Incluso quedó la impresión de que la FECON, o su Presidente Émile Rojas, había apoyado el Combo (Carazo, 2007: entrevista), al menos en lo relativo a la apertura de las telecomunicaciones (Cárdenas, 2007: entrevista), o que se encontraba comprometido con "el oficialismo" (Fournier, 2007: entrevista). El Presidente de FECON también aspiraba a formar parte de la Comisión Mixta como representante ambientalista, pero varias organizaciones proponían a Rolando Portilla del Frente Nacional por los Bosques (entrevistas: Fournier, 2007; Portilla, 2007; Cárdenas, 2007; Rivas, 2007). Se realizó un encuentro entre las organizaciones ambientalistas con el fin de consensuar un representante, pero no hubo una decisión clara, o se pospuso la misma (entrevistas: Portilla, 2007; Macdonald, 2007; Marín, 2007). Finalmente, los dirigentes sindicales y el diputado Merino intervinieron en apoyo de Portilla, quien asumió la representación del sector (entrevistas: Carazo, 2007; Portilla, 2007) $)^{12}$.

La Comisión Especial Mixta es una figura legislativa que integra diputados $y$ personas externas al Congreso. Estas últimas participan en calidad de "asesores" sin derecho a voto. Antes de finalizar su mandato, el grupo de representantes sociales en la Comisión Mixta - conocido como la Representación Social- presentó una propuesta de "Ley de Fortalecimiento del ICE" (Representación Social, 2000 c). El proceso que llevó a este proyecto se basó en más de una veintena de actividades de consulta ciudadana en once comunidades diferentes, más una decena de encuentros con varios sectores sociales (Se Mueve, 2000d). Dicha propuesta recogió los principales planteamientos

\footnotetext{
12 Portilla, además de un vehemente ambientalista era ingeniero del departamento de Planeamiento Ambiental del ICE.
} 
defendidos por el sector ambientalista y comunidades afectadas por la generación hidroeléctrica (Se Mueve, 2000c) $)^{13}$.

\section{BALANCE DE LA PARTICIPACIÓN AMBIENTALISTA}

Las primeras acciones de rechazo a las leyes del Combo las emprendieron los sindicatos del ICE y algunos grupos ambientalistas, antes de la incorporación del sector estudiantil (Salas, 2007: entrevista). Sin embargo, cuando la lucha pasó a las calles, la participación de quienes se identifican como ambientalistas fue muy pequeña. De acuerdo con Portilla, en la marcha del 23 de marzo, la más grande en todo el proceso, "todas" las organizaciones del sector se hicieron presentes, pero no sumaban más de 30 personas (Portilla, 2007: entrevista).

Es interesante señalar aquí un dato sobre la adscripción ambientalista en aquel momento: en mayo de 2000, una encuesta preguntó “Se siente representado en la Comisión Mixta que estudia la Ley del ICE?”. Entre quienes respondieron que sí (43\%), el 6,8\% dijo sentirse representado por los ambientalistas (Unimer, 2000). Eso sugiere que alrededor de un 3\% de la población se identificaba de algún modo con las organizaciones del sector.

Pero el aporte ambientalista a la movilización no se puede juzgar por la cantidad de personas que las organizaciones hayan podido "acarrear" a las distintas protestas. En primer lugar, porque la sensibilidad por los temas ambientales va más allá de quienes se identifican como ambientalistas o ecologistas. Esto se observó en la historia de lucha de los colectivos que se movilizaron en Pérez Zeledón y Cañas (Guanacaste): las personas del Comité de Defensa de los Ríos, o el Comité Cívico de Cañas, "no se reivindican como ambientalistas o como ecologistas [pero] en su agenda tienen

13 La alianza que se opuso al Combo estuvo representada por ocho personas: el diputado José Merino y siete representantes de las organizaciones sociales: Jorge Arguedas, Ricardo Segura y Fabio Chávez, por el Frente Interno de Trabajadores del ICE; Eva Carazo por el movimiento estudiantil; Rolando Portilla por el sector ambiental; Pilar Ureña y William Vargas por la Pastoral Social. ese tipo de preocupaciones" (Cárdenas, 2007: entrevista). Por otra parte, el ambientalismo aportó una perspectiva particular, que incluso fue recogida en los manifiestos sindicales (Cárdenas, 2007: entrevista).

En particular, pareciera que la apertura de los Parques Nacionales a proyectos de generación de energía fue uno de los temas que mayor rechazo generó entre la población (entrevistas: Cárdenas, 2007; Macdonald, 2007; Marín, 2007). Eva Carazo, entonces Presidenta de la Federación de Estudiantes de la Universidad de Costa Rica (UCR), confirmó que ese fue un asunto "muy importante" entre los universitarios: "era uno de los temas sobre lo que sacábamos mucho material, era como de los argumentos fuertes que sabías que iban a tocar a la gente" (Carazo, 2007: entrevista). Dicha preocupación también se vivió en la Península de Osa, en el sur del país, donde el grupo local que había participado en la "campaña por los bosques de Osa" sentía que el Combo era otra amenaza a la biodiversidad de la zona, en este caso al Parque Nacional Corcovado (Marín, 2007: entrevista).

Lamentablemente, ninguno de los estudios de opinión de la época puede confirmar estas apreciaciones. Un sondeo realizado por la UCR a finales de marzo se preguntó "¿Qué es lo primero que se le ocurre cuando se habla del 'Combo del ICE'?". El estudio solo recogió el primero de los temas mencionados por cada informante. Ciertamente no era el ambiente o los parques nacionales lo que más preocupaba sobre el Combo. Ante la pregunta indicada, el tema ambiental podría haber aparecido como segunda o tercera opción, pero casi nunca fue la primera respuesta, tanto así que los "problemas ambientales" se incluyeron en la categoría de "Otros" (16\%). Tampoco se preguntó directamente cuáles eran las razones de quienes se mostraron en desacuerdo con el Combo (Campos y Raventós, 2004). Queda la duda, entonces, en qué medida lo ambiental fue un asunto que motivara a la movilización popular. En todo caso, el Poder Ejecutivo y los partidos mayoritarios ratificaron que el sector ambientalista tenía peso en la opinión pública cuando pactó su integración a la Comisión Mixta. 
LAS MOTIVACIONES AMBIENTALISTAS: LA CRÍTICA DISTRIBUTIVA Y LA CRÍTICA ECOLÓGICA

Al indagar en las implicaciones ambientales del Combo, sobresalen dos temas: el fomento a la producción hidroeléctrica y la intervención de los Parques Nacionales para producción geotérmica.
Las distintas agrupaciones ambientalistas $y$ comunales rechazaron la desregulación en el uso de los ríos, ya fuera por su impacto socio-ambiental, o porque el Combo no favorecía una gestión integral de las cuencas (Véase Recuadro 1).

RECUADRO 1. OBJECIONES AMBIENTALISTAS AL COMBO: RIESGOS AMBIENTALES, SOCIALES Y CULTURALES

Uso de los ríos: la generación de electricidad tendría prioridad en el uso de los ríos, en perjuicio de otros usos ya establecidos (domésticos, agrícolas, de abrevadero de ganado, turísticos, de transporte, de recreación, entre otros). El Combo no incorporaba criterios de planificación de cuencas "de manera integral y multidisciplinaria".

La ley se había elaborado y aprobado sin una adecuada participación de los sectores interesados. Además, excluía la participación de "las comunidades en la toma de decisiones sobre eventuales proyectos hidroeléctricos".

Se autorizaban expropiaciones a favor de empresarios privados, en terrenos del Estado, áreas protegidas privadas y tierras de agricultores.

Se debilitaba la función reguladora del MINAE.

La composición del Consejo Técnico del CENPO, institución rectora del sector energético, reunía exclusivamente "técnicos profesionales en el campo eléctrico", excluyendo la participación de otros sectores como ambientalistas, consumidores finales, comunidades rurales e indígenas.

Creaba incentivos para generación térmica (con hidrocarburos) pero no la investigación ni aplicación de fuentes sustentables.

Sentaba un precedente para la apertura de los Parques Nacionales y otras áreas protegidas a actividades extractivas y turismo a gran escala.

Fuente: FECON (2000b) y FECON (2000c)

Adicionalmente, existía una mala experiencia con las leyes 7200 y 7508 , conocidas como las leyes de "co-generación", que habían permitido a los productores privados de electricidad colocar sus excedentes en la red de distribución nacional. Esa legislación en ningún momento favoreció la autosuficiencia eléctrica de comunidades o del sector privado, si no que generó un negocio en el que participaron figuras de la política nacional (ICE, 1999), ya fuera en calidad de inversionistas, constructores o consultores (firmas de abogados, de ingeniería, etc. ${ }^{14}$. El Combo otorgaba nuevos incentivos

14 Por ejemplo, en el caso del proyecto Los Gemelos, en Pérez Zeledón, la empresa era representada por el bufete de Rolando Laclé, ex-ministro de a la co-generación pues permitía que un generador privado individual pudiera poseer hasta un $25 \%$ de la capacidad instalada total del país (Artículo 60 de la Ley del Combo, expediente 13 873, en Asamblea Legislativa, 2000).

No fue una demanda del movimiento derogar las leyes de co-generación, pero ya existía una posición crítica a las mismas (entrevistas: Portilla, 2007; Rivas, 2007; Fournier, 2007; Ureña, 2007). El tema sí surgió en los debates internos de la Representación Social y se reflejó en su propuesta de Ley, que eliminaba la cogeneración privada, excepto en el caso de cooperativas rurales. Eliminar la co-generación fue

la Presidencia y varias veces diputado del PUSC (Ureña, 2007: entrevista). 
un tema en el que los ambientalistas -Portilla y Ureña insistieron más que los mismos sindicatos (entrevistas: Carazo, 2007; Salas, 2007).

Pero la desregulación de la generación hidroeléctrica no fue el tema ambiental que más preocupó a las organizaciones ambientalistas más activas en esta lucha, si no la geotermia en Parques Nacionales. Portilla señaló que "el tema fundamental quizás era la apertura de las áreas protegidas. Ese era un punto que el sector ambiental no lo aceptaba bajo ninguna condición" (2007: entrevista). El entonces Presidente de APREFLOFAS se expresó en términos similares: "el Combo tenía muchos matices, pero el que más preocupaba era la posibilidad de que se pudieran efectuar proyectos dentro de parques naturales" (Marín, 2007: entrevista). También para FECON era el tema más delicado (Macdonald, 2007: entrevista): “eso podría ser el portillo para que se abrieran los parques a proyectos hidroeléctricos. Era como una cuestión de principio no abrir del todo porque eso se trae al suelo el carácter inmaculado de los parques nacionales (Cárdenas, 2007: entrevista).

\section{CRÍTICA DISTRIBUTIVA Y CRÍTICA ECOLÓGICA}

Los argumentos contra el Combo se pueden analizar en términos de una crítica distributiva y una crítica ecológica. La crítica distributiva se ocupa de la distribución socioecológica, es decir, de las desigualdades sociales, geográficas o inter-generacionales en el disfrute de los bienes y servicios ambientales ${ }^{15}$. Por ejemplo, la concentración de la propiedad de la tierra es un elemento muy importante de la distribución socio-ecológica en una sociedad ${ }^{16}$. Pero la distribución socio-ecológica no se refiere solo a los recursos naturales tangibles si no a toda una serie de servicios ambientales basados en distintas funciones de

$\overline{15}$ Martínez-Alier (2004) habla de "distribución ecológica”, pero la ciencia biológica de la ecología ya hace uso de dicho término en un sentido distinto.

16 De allí que la conflictividad agraria se pueda entender como parte de la conflictividad ambiental, junto a los conflictos por el acceso al agua, a los espacios naturales para la recreación, etc. los ecosistemas ${ }^{17}$, de modo que la crítica distributiva refiere también a los riesgos sociales provocados por los daños causados a las funciones ecosistémicas. Por otra parte, la crítica ecológica se refiere al impacto de las actividades humanas en la naturaleza, en el funcionamiento de los ecosistemas. La crítica ecológica se expresa la mayoría del tiempo con términos provenientes de las ciencias naturales. Pero la crítica ecológica puede también derivarse de cosmovisiones indígenas opuestas al dominio de la razón instrumental sobre la naturaleza.

La crítica distributiva frente al Combo se observa claramente en las inquietudes del Comité de Defensa de los Ríos de Pérez Zeledón, grupo que fue "fundamental" en la movilización de San Isidro durante el Combo (Ureña, 2007: entrevista). La historia de este Comité comienza en 1995 en el distrito de Rivas de Pérez Zeledón, donde varias familias corrían el riesgo de ser expropiadas o tener que aceptar servidumbres forzosas en sus terrenos. La parte a favorecer por esas medidas era una empresa de capital español, Producciones Antheus SA, que pretendían realizar dos proyectos hidroeléctricos sobre el río Chirripó Pacífico (o General), conocidos como Los Gemelos (nominalmente, proyectos San Luis I y San Luis II). Poco a poco Los Gemelos pasaron a ser objeto de preocupación de las comunidades ribereñas, ya no solo de las familias directamente afectadas en sus tierras (Ureña, 2007: entrevista). Más aún, se conoció de planes para otros cuatro proyectos hidroeléctricos a realizar en los ríos Chirripó Pacífico y Buena Vista. En octubre de 1996 la Diócesis convocó a una actividad informativa sobre esta situación, de la que resultó el Comité de Defensa de los Ríos, con representantes de 23 comunidades, de los distritos de Rivas, General Viejo y Daniel Flores, de Pérez Zeledón (Pacheco, 2000; Ureña, 2007: entrevista).

El caso de Los Gemelos también puede ilustrar cómo una lucha que inicialmente se

17 Los servicios ambientales pueden definirse como beneficios que los seres humanos obtienen de forma directa o indirecta de cuatro tipos de funciones ecosistémicas: funciones de regulación, de hábitat, de producción, de información y de sustrato (Gómez-Baggethun y de Groot, 2007). 
limita al tema de la propiedad de la tierra puede enriquecerse con cuestionamientos propios de una crítica ecológica, lo que a su vez enriquece la crítica distributiva originalmente centrada en la cuestión de la tierra:

- La primera reacción de todos nosotros fue muy primaria, muy territorial. Sin embargo iniciamos un proceso tan exhaustivo de investigación que el asunto de las tierras, después fue desplazándose por el tema de la falta de agua. Entramos en contacto con las comunidades de Sarapiquí y San Carlos para conocer sus experiencias y nos aterró ver los ríos, en el estado de deterioro que quedaban después de cada toma de agua (Ureña, 2007: entrevista).

En el caso del Combo, la crítica ecológica fue aportada por las organizaciones ambientalistas y comunales. La intervención de los ríos era común a estos dos sectores, y tenía implicaciones distributivas y ecológicas. Por otra parte, el rechazo a la apertura de los Parques Nacionales para la producción geotérmica tomó la forma de una crítica (casi) exclusivamente ecológica (por su impacto en los ecosistemas protegidos). Sin embargo, hay un elemento distributivo implícito cuando se reivindica la defensa de los Parques Nacionales como defensa del patrimonio público:

- Se trataba de privatizar el patrimonio público, y privatizar no sólo pasa por la propiedad formal, pasa por privatizar el disfrute de determinados bienes, ponerlos al servicio de un sector (Cárdenas, 2007: entrevista).

\section{EL COMBO COMO EXPRESIÓN DEL SOCIO- AMBIENTALISMO}

Se ha propuesto el término de socioambientalismo para hablar de "los movimientos sociales influenciados por el ambientalismo" (Viola, 1992). Desde otra perspectiva, el socio-ambientalismo es la convergencia entre la crítica distributiva reconocible en los movimientos sociales "clásicos" (en torno a los recursos naturales, o su equivalente monetario: el salario) y la crítica ecológica de origen ambientalista:

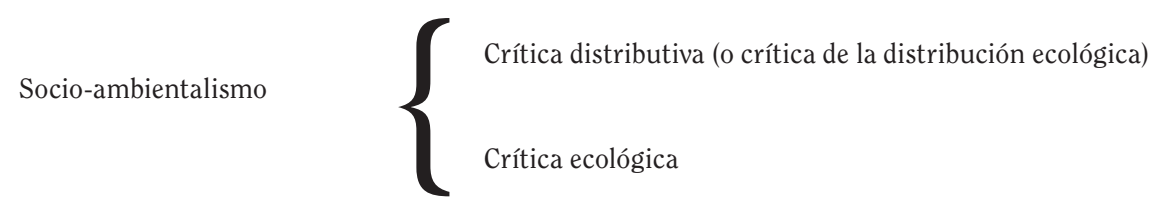

En tanto alianza multi-sectorial, el Combo permite explorar el proceso de convergencia socio-ambientalista en Costa Rica. Dado que fue una lucha en contra de la privatización de los servicios de electricidad y telecomunicaciones, allí se sumaron sindicatos, partidos de izquierda o centro-izquierda, movimientos sociales y sectores identificados con el Estado desarrollista cuyo símbolo era el ICE. También era de esperar que se sumara el "ambientalismo crítico", es decir, la corriente ambientalista que identifica en el capitalismo - su lógica, sus instituciones - el responsable último de la destrucción ambiental (Cordero, 2007: 220). Pero no fueron las organizaciones del ambientalismo crítico las que tomaron la iniciativa frente al Combo, si no las asociaciones Yiski y APREFLOFAS, clasificadas como "conservacionistas" en algunos estudios, pues se asume que su preocupación principal es la conservación de ecosistemas y especies naturales sin llegar a desplegar una crítica radical del sistema político o económico (Mora, 1998: 130; Cordero, 2007: 220).

Pero tanto Yiski como APREFLOFAS tienen una historia de pronunciamientos críticos ante políticas y proyectos desarrollistas, a diferencia de las ONG estrictamente conservacionistas ${ }^{18}$.

18 Esas últimas enfocadas en el manejo de ecosistemas, normalmente desentendidas de toda lucha social o controversia pública. Algunas de ellas 
Por ejemplo, ambas organizaciones han tomando parte en las campañas más emblemáticas del ambientalismo costarricense en los últimos 15 años, tales como la lucha contra Ston Forestal, contra la minería de oro a cielo abierto y contra el TLC con Estados Unidos. Es más, ambas organizaciones critican la falta de beligerancia de las ONG conservacionistas, a las que ven distanciadas de "la temática social" (Marín, 2007: entrevista), incluso como una "mafia verde" neoliberal (Fournier, 2007: entrevista).

Yiski y APREFLOFAS no dejaron de pronunciarse sobre las implicaciones distributivas y socio-políticas del Combo (FNB, 2000) ${ }^{19}$. De hecho, todas las personas del movimiento ambientalista consultadas para esta investigación estuvieron de acuerdo con mantener los servicios de electricidad y telecomunicaciones bajo potestad estatal, incluyendo la generación de electricidad, limitando o eliminando la cogeneración privada. En palabras de una de las entrevistadas:

- Había un sentido de apropiación de lo que el ICE hace y significa. Eso era común a todos los sectores. [Pregunta: ¿Incluso los ambientalistas?] Sí, algo que la gente defendía con unanimidad era el acceso universal, solidario de los servicios [...] Y eso se defendía por igual en todos los sectores. Y yo estoy muy segura que la gente con un sentimiento básicamente ambientalista también reconocía eso como un valor. Es que no es gente absolutamente conservacionista (Salas, entrevista: 2007).

\section{EL PROYECTO DE LEY DE LA REPRESENTACIÓN SOCIAL}

La Representación Social emprendió la redacción de una propuesta de Ley de

dirigidas por funcionarios que con facilidad pasan de la administración pública al mundo de las ONG, $y$ viceversa.

19 Se trata de una propuesta o manifiesto suscrito por Marín, Fournier y Portilla como "coordinadores nacionales" del Frente Nacional por los Bosques.
Fortalecimiento del ICE, proceso en el que fueron conociéndose las visiones comunes y las diferencias. Ureña y Vargas, de Pastoral Social, buscaron aumentar las oportunidades de participación y fiscalización ciudadana sobre los proyectos hidroeléctricos (Ureña, 2007: entrevista). El sector ambientalista apoyó esta postura y también aspiraba a que el ICE desarrollara otras alternativas energéticas, además se opuso a la generación de energía en Parques Nacionales. Ambos sectores también querían limitar la cogeneración privada de electricidad. Estas reivindicaciones tuvieron que ser debatidas con los representantes sindicales, renuentes a limitar las potestades del ICE (entrevistas: Ureña, 2007; Carazo, 2007).

Fue necesario realizar algunas sesiones de "resolución de conflictos" para superar las diferencias y llegar a una propuesta de ley consensuada (Portilla, 2007). El documento recogió las principales demandas del sector comunal y ambientalista: en el artículo 37, por ejemplo, se lee que "el ICE deberá respetar la voluntad, decisiones y realidad cultural de las comunidades afectadas" y manda la aplicación de mecanismos de información y consulta para hacer "efectiva la participación ciudadana en la toma de decisiones sobre proyectos". El artículo 38 indica similares procedimientos en los territorios indígenas. Y el artículo 39 señala que "en virtud de la importancia ecológica $y$ social presente $y$ futura de los Parques Nacionales y las Reservas Biológicas, el ICE no desarrollará proyectos de electricidad ni de telecomunicaciones dentro de estas áreas" (Representación Social, 2000c). En materia de participación ciudadana, el proyecto creaba espacios de consulta $y$ toma de decisiones por medio de las Juntas Regionales y en el ámbito de la Junta Directiva. También se derogaban las leyes 7200 y 7508, de modo que la generación eléctrica con fines de servicio público habría de ser realizada solo por el ICE, las empresas públicas y cooperativas de electrificación rural (Se Mueve, 2000d). En palabras de un entrevistado, ese proyecto "es una belleza política. Es inclusivo, es respetuoso, marca una tendencia hacia la sustentabilidad, es nacionalista" (Rivas, 2007: entrevista). 
LOS LÍMITES DE LA ALIANZA Y LA HERENCIA DEL COMBO

Antes de la lucha contra el Combo, las campañas ambientalistas más importantes en la historia del país se presentaron como alianzas entre agrupaciones ambientalistas $y$ grupos comunales, campesinos o indígenas (Cordero, 2007). El Combo fue la primera de estas alianzas multi-sectoriales donde coincidieron ambientalistas $y$ un sector del sindicalismo costarricense.

Pero el Combo también ilustra la fragilidad del socio-ambientalismo fraguado en dichas alianzas. Existía un compromiso para buscar la aprobación del proyecto de ley elaborado por la Representación Social, y se esperó a que las elecciones de 2002 ofrecieran condiciones más favorables para ello. Sin embargo, en el año 2003, las organizaciones sindicales del ICE impulsaron una propuesta de ley distinta, lo cual hizo que resurgieran, con más fuerza, sus diferencias con las organizaciones comunales y ambientalistas. El punto de discordia era precisamente las regulaciones socio-ambientales a la actividad hidroeléctrica: un grupo de dirigentes sindicales decidieron "dejar de lado todo lo que era ambiental, participación [ciudadana], consultas, porque su preocupación era quitarle amarras al ICE y que pudiera funcionar con más margen de acción" (Carazo, 2007: entrevista).

Ello tuvo consecuencias para la campaña contra el TLC, pues se presentaron dos posturas distintas en el movimiento ambientalista y comunal: un sector que rechazaba trabajar junto al sector sindical y otro que sí permaneció en los mismos espacios de coordinación donde participaban los sindicatos del ICE (entrevistas: Fournier, 2007; Rivas, 2007; Cárdenas, 2007).

A pesar de ello, puede que el Combo haya dejado un aprendizaje importante para ambientalistas y sindicalistas dispuestos a reconocer la existencia de intereses comunes entre dichos sectores:

-... Hay cuadros [sindicales] sumamente valiosos: gente que trabaja en el AyA, en el MINAE, en la Municipalidad... con la que nunca nos habíamos planteado nada, ahora sí, podemos sacar un comunicado conjunto, ir a gestionar algo. Hay otros con los que ahora tenemos mejor criterio para decir no. Antes era una cuestión más de intuición. Ahora hay una experiencia para decir con estos sí con estos no (Cárdenas, 2007: entrevista).

Por otra parte, agrega Cárdenas, las diferencias identitarias y temáticas entre las organizaciones sociales tienen relevancia para las "cúpulas y burocracias", pero en el ámbito local ello no impide a las personas formar alianzas en torno a lo ambiental:

- Al nivel de (sic) las regiones vos ves a las seccionales de los sindicatos del ICE hablando del tema de las playas, pero no como un tema postizo, no como un tema que asumieron de otro, si no como un tema propio. El tema de la privatización de Cabuyal, la privatización de Papagayo... vos ves a los sindicalistas del ICE en Liberia, que están metidos en las comisiones. Al nivel regional el tema ambiental está mucho más incorporado a la vida cotidiana que para nosotros (Cárdenas, 2007: entrevista).

Al respecto, es importante indicar que el Combo le dio una dimensión nacional a procesos como el vivido en Rivas de Pérez Zeledón con el proyecto Los Gemelos. Se había pasado por alto que de 1990 al año 2000 se construyeron unas 27 plantas hidroeléctricas privadas de pequeña $y$ mediana capacidad, bajo el amparo de las leyes de co-generación (ICE: 2003, diapositiva nro. 41 "Plantas de Generación Privada"). Ello había resultado en una docena de conflictos locales, aproximadamente (FECON, 2003). Uno de los efectos del Combo fue la realización, en el año 2001, de un Foro Nacional sobre Represas Hidroeléctricas y Comunidades, donde representantes comunales pudieron intercambiar sus experiencias. Dos años después se realizó un segundo foro con igual temática (FECON, 2003).

En conclusión, si bien el proceso de convergencia socio-ambientalista ha prosperado de forma limitada en cuanto a las estructuras 
sindicales, ha continuado fortaleciéndose por la vía de las organizaciones de base local. Dos factores que favorecen dichos acercamientos son la apertura de las organizaciones comunales hacia inquietudes ecológicas (crítica ecológica) $y$ la sensibilidad de un sector del ambientalismo hacia reivindicaciones en torno a la distribución socio-ecológica (crítica distributiva).

\section{FUENTES CONSULTADAS}

BIBLIOGRAFÍA Y DOCUMENTOS

Comisión Mixta de la Asamblea Legislativa. "Acuerdo del Diálogo Nacional". Hoja volante mimeografiada. 4 de abril de 2000.

Asamblea Legislativa. "Ley para el Mejoramiento de los Servicios Públicos de Electricidad y Telecomunicaciones $y$ de la participación del Estado". Suplemento Especial, La Nación. Costa Rica. 26 de marzo de 2000.

Campos, Domingo y Raventós, Ciska. "Combo del ICE en el momento culminante de las protestas. Sondeo telefónico 24-25 de marzo de 2000". Revista de Ciencias Sociales 106 (IV) y 107 (I). Costa Rica. 2004-2005.

Cordero, Allen. "Bosque, agua y lucha. Movimientos ambientalistas en Costa Rica”. Hurtado, M. y Lungo, I. (Comp.). Aproximaciones al movimiento ambiental en Centroamérica.1a. Edición. Guatemala: FLACSO, 2007.

FECON y RCRN. Sin título (carta enviada por la Federación Costarricense de la Conservación de la Naturaleza y la Red Costarricense de Reservas Naturales a la Comisión de Gobierno $y$ de Administración de la Asamblea Legislativa). 15 de enero de 1999.
FECON. "Mociones de FECON al 'Combo Eléctrico". Borrador interno. 21 de enero de 2000(a). Archivo FECON.

FECON. “¿Está usted de acuerdo que se desarrollen proyectos energéticos en los parques nacionales y reservas naturales privadas, para el beneficio de unos cuantos?". La Nación. Costa Rica. 24 de enero de 2000(b): 21A.

FECON. "Comunicado". Se Mueve. Costa Rica. Marzo de 2000(c). [En línea]. En: <http:// semueve.netfirms.com/doc_combo/ comunicado_fecon_a.htm>

FECON. Memoria del II Foro Nacional de Comunidades Frente a la Expansión Hidroeléctrica. Costa Rica: FECON, marzo de 2003.

FNB. "Propuesta del Frente Nacional por los Bosques, para una modernización del ICE”. Enero de 2000. Mimeo.

Fuentes Belgrave, Laura. "Las tres semanas del "combo" ". Se Mueve .Costa Rica. Marzo de 2001. [En línea]. En: <http:// semueve.netfirms.com/arch_ice/03_01_ aniversario_combo_cronica. htm> [Consultada el 14-08-2000].

Gómez-Baggethun, E. y de Groot, R. "Capital natural y funciones de los ecosistemas: explorando las bases ecológicas de la economía”. Revista Ecosistemas 16 (3). España. Asociación Española de Ecología Terrestre, septiembre de 2007: 4-14. [En línea] En: <http://www. revistaecosistemas.net/pdfs/496.pdf> [Consultada el 15-03-2008].

Herrera, Mauricio y Vargas, A. "Tema ambiental enciende pugna”. La Nación. Costa Rica. 26 de enero de 2000. [En línea]. En: <http://www.nacion.com/ln_ee/2000/ enero/26/pais1.html> [Consultada el 14-08-2000]. 
ICE. "Oficio PE-033-99P remitido al diputado Célimo Guido, de la fracción del Partido Fuerza Democrática". Asamblea Legislativa. 29 de enero de 1999. Mimeo.

ICE. Sector electricidad en Costa Rica. Comisión Especial Mixta de la Asamblea Legislativa. San José, Costa Rica. 9 de abril de 2003. [En línea]. En: <http://

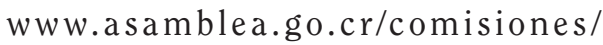
electricidad.pps $>$ [Consultada el 12-082009].

Instituto Costarricense de Electricidad. Plan de expansión de la generación eléctrica. Período 2006-2025. ICE. Centro Nacional de Planificación Eléctrica Proceso Expansión Integrada. San José, Costa Rica. Enero de 2006. [En línea]. En: <http://www.ice.go.cr/esp/ ele/planinf/Plan_Expansion_de_la_ Generacion_2005.pdf>

Martínez-Alier, Joan. "Los conflictos ecológicodistributivos y los indicadores de sustentabilidad". Revista Iberoamericana de Economía Ecológica 1. 2004: 21-30. [En línea]. En: <http://iis.ucr.ac.cr/ pagWeb/actividades/martinezalier.pdf> [Consultada el 10-10-2005 ].

Méndez, William. "Aprobado subsidio eléctrico". La Nación. Costa Rica. 19 de noviembre de 1998. [En línea]. En: <http://www. nacion.com/ln_ee/1998/noviembre/19/ pais1.html> [Consultada el 12-08-2009].

Mora Castellano, Eduardo. Naturaleza quéherida mía. Ambientalismo, Estado, natura y mercado. Costa Rica: Ambientico Ediciones, 1998.

Pacheco, Freddy. "La conspiración hidroeléctrica: los casos Chachagua y Rivas". Ambientico 80. Costa Rica. Mayo de 2000: 7.

Portilla, Rolando. "La lucha ambiental durante el combo". (s.f.). Mimeo.
Representación Social. "Plan de Contingencia para el fortalecimiento del ICE". 11 de setiembre de 2000(a). Mimeo.

Representación Social. "Diez principios para una ley de fortalecimiento del ICE". Costa Rica. 20 de octubre de 2000(b). Mimeo.

Representación Social. "Propuesta de Ley de Fortalecimiento del ICE". Costa Rica. Noviembre de 2000(c). Mimeo.

Se Mueve. "Foro 'Jesús Martínez' resalta papel de comunidades en lucha contra el combo". Se Mueve. Costa Rica. 3 de abril de 2000(a). [En línea]. En: <http:// semueve.netfirms.com/arch_combo/ sm_03_04_2000_01.htm> [Consultada el 12-08-2009].

Se Mueve. "Huelga Nacional". Se Mueve. Costa Rica. 4 de abril de 2000(b). [En línea]. En: <http://semueve.netfirms.com/ arch_combo/sm_04_04_2000_01.htm> [Consultada el 12-08-2009].

Se Mueve. "Proyecto de Ley alternativo: El ICE sería más responsable con el ambiente". Se Mueve. Costa Rica. 19 de noviembre de 2000(c). [En línea] <http://semueve. netfirms.com/arch_ice/ley_ambiente. htm> [Consultada el 12-08-2009].

Se Mueve. "Sectores sociales proponen Ley de Fortalecimiento del ICE". Se Mueve. Costa Rica. 19 de noviembre de 2000(d). [En línea]. En: <http://semueve.netfirms. com/arch_ice/proponen_ley.htm> [Consultada el 12-08-2009].

UNIMER. "Segunda Encuesta Nacional de Opinión”. La Nación. Sexta parte: Comisión Mixta. Costa Rica. 21 de junio de 2000. [En línea]. En: <http:// www.nacion.com/ln_ee/encuestas/ unimer/6-2000/Parte6.htm> [Consultada el 20-08-2009]. 
Venegas C., Ismael. "Avanza transformación del ICE". La Nación. Costa Rica. 21 de diciembre de 1999. [En línea]. En: <http://www.nacion.com/ln_ee/1999/ diciembre/21/pais1.html> [Consultada el 12-08-2009].

ENTREVISTAS

Arguedas, Jorge. Presidente de la Asociación Nacional de Técnicos y Trabajadores de la Energía y las Telecomunicaciones (ANTTEC). Representante sindical ante la Comisión Especial Mixta de la Asamblea Legislativa (2000-2001). Costa Rica. 30 de abril de 2009 .

Carazo, Eva. Ex-presidenta de la Federación de Estudiantes de la Universidad de Costa Rica (FEUCR). Representante estudiantil ante la Comisión Especial Mixta de la Asamblea Legislativa (2000-2001). Costa Rica. 29 de marzo de 2007.

Cárdenas, Pablo. Presidente de la Federación Costarricense para la Conservación del Ambiente (FECON). Costa Rica. 8 de febrero de 2007.

Macdonald, Isabel. Ex-directora Ejecutiva de la Federación Costarricense para la Conservación del Ambiente (FECON).
Costa Rica. 7 de marzo y 3 de abril de 2007.

Marín, Luis Diego. Asociación Preservacionista de Flora y Fauna Silvestre (APREFLOFAS). Costa Rica. 12 de febrero de 2007.

Fournier, Ma. E. Presidenta de la Asociación Conservacionista Yiski. Costa Rica. 9 de febrero de 2007.

Portilla, Rolando. Asociado de APREFLOFAS y colaborador de Yiski. Representante por el sector ambientalista ante la Comisión Especial Mixta de la Asamblea Legislativa (2000-2001). Costa Rica. 6 de febrero de 2007.

Rivas, Gabriel. Asociación Comunidades Ecologistas La Ceiba (COECO-Ceiba). Costa Rica. 9 de febrero de 2007.

Salas, Seidy. Grupo Germinal y Comisión de Enlace y Seguimiento (CONAES). Costa Rica. 1 de febrero de 2007.

Ureña, Pilar. Asociación Montaña Verde y Comité de Defensa de los Ríos (Pérez Zeledón). Representante ante la Comisión Especial Mixta de la Asamblea Legislativa (2000-2001). Costa Rica. 29 de marzo de 2007. 
